\title{
Activation Reduction Method for a Concrete Wall in a Cyclotron Vault
}

\author{
Masaaki Kumagai ', Kohsuke Sodeyama', Yukio Sakamoto ${ }^{1}$, Akihiro Toyoda ${ }^{2}$, Hiroshi Matsumura², Takayoshi Ebara', \\ Taichi Yamashita', Kazuyoshi Masumoto ${ }^{2, *}$
}

${ }^{1}$ ATOX Co., Ltd, Tokyo, Japan; ${ }^{2}$ Radiation Science Center, High Energy Accelerator Research Organization, Tsukuba, Japan

\section{Original Research}

Received October 4, 2016

Revision May 11,2017

Accepted August 22, 2017

\section{Corresponding author:}

Kazuyoshi Masumoto

Radiation Science Center, High Energy Accelerator Research Organization, 1-1

Oho, Tsukuba 305-0801, Japan

Tel: +81-29-864-5492,

Fax: +81-29-864-1993,

E-mail:kazuyoshi.masumoto@kek.jp

This is an Open-Access article distributed under the terms of the Creative Commons Attribution NonCommercial License (http://creativecommons.org/ licenses/by-nc/4.0) which permits unrestricted noncommercial use, distribution, and reproduction in any medium, provided the original work is properly cited.

Copyright $\odot$ 2017The Korean Association for Radiation Protection

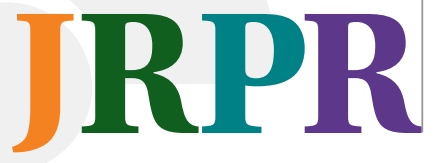

Background: The concrete walls inside the vaults of cyclotron facilities are activated by neutrons emitted by the targets during radioisotope production. Reducing the amount of radioactive waste created in such facilities is very important in case they are decommissioned. Thus, we proposed a strategy of reducing the neutron activation of the concrete walls in cyclotrons during operation.

Materials and Methods: A polyethylene plate and B-doped $\mathrm{Al}$ sheet (30 wt\% of B and $2.5 \mathrm{~mm}$ in thickness) were placed in front of the wall in the cyclotron room of a radioisotope production facility for pharmaceutical use. The target was Xe gas, and a Cu block was utilized for proton dumping. The irradiation time, proton energy, and beam current were 8 hours, $30 \mathrm{MeV}$, and $125 \mu \mathrm{A}$, respectively. To determine a suitable thickness for the polyethylene plate set in front of the $\mathrm{B}$-doped $\mathrm{Al}$ sheet, the neutron-reducing effects achieved by inserting such sheets at several depths within polyethylene plate stacks were evaluated. The neutron fluence was monitored using an activation detector and 20-g on de Au foil samples with and without 0.5 -mm-thick $\mathrm{Cd}$ foil. Each Au foil sample was pasted onto the center of a polyethylene plate and B-doped $\mathrm{Al}$ sheet, and the absolute activity of one Au foil sample was measured as a standard using a Ge detector. The resulting relative activities were obtained by calculating the ratio of the photostimulated luminescence of each foil sample to that of the standard Au foil.

Results and Discussion: When the combination of a 4-cm-thick polyethylene plate and Bdoped $\mathrm{Al}$ sheet was employed, the thermal neutron rate was reduced by $78 \%$.

Conclusion: The combination of a 4-cm-thick polyethylene plate and B-doped $\mathrm{Al}$ sheet effectively reduced the neutron activation of the investigated concrete wall.

Keywords: Neutron shield, Low activation, Cyclotron, Polyethylene, B-doped Al

\section{Introduction}

Since 2003, compact cyclotrons for producing labeled compounds for positron emission tomography (PET) have become more widely used in Japan. Currently, more than 150 cyclotrons are installed in hospitals. The typical radioisotopes employed for PET are ${ }^{11} \mathrm{C},{ }^{13} \mathrm{~N},{ }^{15} \mathrm{O}$, and ${ }^{18} \mathrm{~F}$. In particular, ${ }^{18} \mathrm{~F}$ is used in almost all hospitals. Activation is primarily caused by thermal neutrons produced by nuclear reactions within the target. When ${ }^{18} \mathrm{~F}$ is produced via the ${ }^{18} \mathrm{O}(\mathrm{p}, \mathrm{n}){ }^{18} \mathrm{~F}$ reaction, $10^{5}-10^{6} \mathrm{~cm}^{-2} \cdot \mathrm{s}^{-1}$ thermal neutrons are distributed throughout the cyclotron vault. Moreover, the shielding concrete inside the cyclotron vault is exposed to neutrons. Fast neutrons are also emitted by the target and penetrate the concrete wall. After a long period of operation, the primary isotopes re- 
maining active in the concrete are ${ }^{152} \mathrm{Eu}$ and ${ }^{60} \mathrm{Co}$, which are produced by thermal neutron capture reactions. Even though the abundances of the target elements Eu and Co are only $10 \mathrm{mg} \cdot \mathrm{kg}^{-1}$ and $1 \mathrm{mg} \cdot \mathrm{kg}^{-1}$, respectively, these elements have large thermal neutron activation cross-sections. After 20 years of operation, these specific activities will exceed the order of the clearance level $\left(0.1 \mathrm{~Bq} \cdot \mathrm{g}^{-1}\right)$. Consequently, the decommissioning cost might be increased due to large amounts of radioactive waste in the concrete. Therefore, reducing the amount of radioactive waste is an important issue affecting decommissioning [1-5].

When the currently existing PET facilities were constructed, activation of the housing was not seriously considered. If this problem had been recognized at the time of construction, self-shielding or low-activation concrete might have been adopted as the housing concrete. However, the adoption of such methods is impossible for the cyclotron facilities already in operation [6].

To develop a new method of reducing the residual activities of the concrete walls in the cyclotron facilities currently in operation, we investigated the use of an additional shield for neutron absorption.

\section{Materials and Methods}

\section{Materials}

Polyethylene is a suitable candidate for neutron thermalization. The polyethylene selected for this study was a stan- dard type $\left(0.96 \mathrm{~g} \cdot \mathrm{cm}^{-3}\right)$.

$B$ is the most effective element for thermal neutron absorption. We did not use polyethylene doped with $B$ because we considered that it could be better to separate the roles of thermalization of fast neutrons and absorption of thermal neutrons. The $\mathrm{B} 4 \mathrm{C}$ powder was sandwiched with $\mathrm{Al}$ sheets to become $30 \mathrm{wt} \%$ of $\mathrm{B}$. The thickness of the sheet was $2.5 \mathrm{~mm}$.

To determine the polyethylene thickness necessary to thermalize neutrons, several polyethylene plates of different thicknesses were tested. To monitor the neutron fluence, 0.6 -cm-diameter, 20 - $\mu \mathrm{m}$-thick Au foil was pasted onto the center of each polyethylene plate and $\mathrm{Al}$ sheet. Several $\mathrm{Au}$ foil samples with and without 0.5 -mm-thick $\mathrm{Cd}$ coating were pasted onto the concrete wall inside the irradiation room and the polyethylene blocks to monitor the thermal and epithermal neutron fluences.

\section{Irradiation setup}

Irradiation was performed at a cyclotron facility used to produce commercially available radioisotopes for radiopharmaceutial use. The target was Xe gas, and a Cu block was employed for proton dumping. The proton energy, beam current, and irradiation time were $30 \mathrm{MeV}, 125 \mu \mathrm{A}$, and approximately 8 hours, respectively. Figure 1 depicts the layout of the irradiation room. Two stacks of polyethylene plates ( $30 \mathrm{~cm} \times 40 \mathrm{~cm}$ ), each of which contained several thin plates with different thickness and had a total thickness of $160 \mathrm{~mm}$, were set in the irradiation room in front of the wall down-
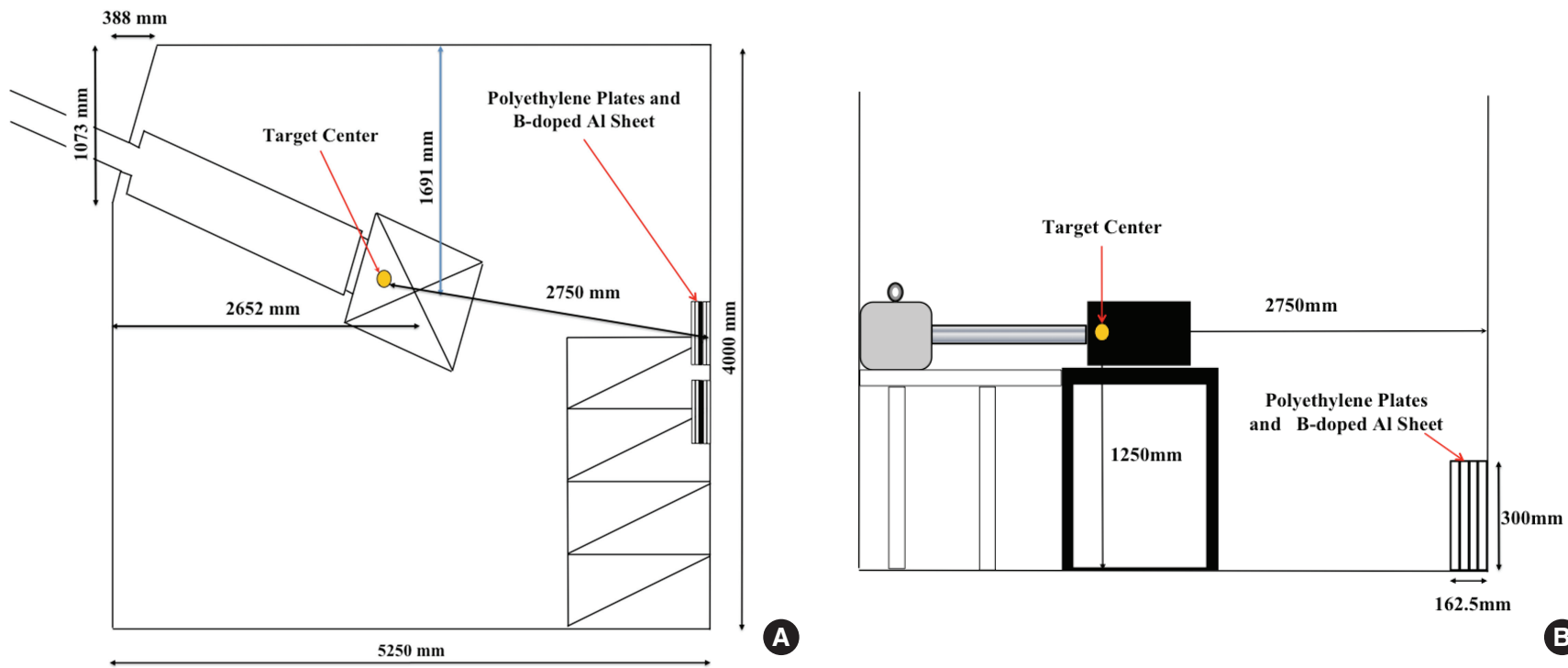

Fig. 1. Irradiation room layout. (A) Plan of irradiation room, (B) Vertical outline. 
stream from the proton beam.

Three types of polyethylene stacks were prepared: one containing polyethylene only (Case 1) and one each with a B-doped Al sheet inserted $4 \mathrm{~cm}$ (Case 2) and $8 \mathrm{~cm}$ (Case 3) beneath the surface of the stack. Figure 2 illustrates Case 2. The polyethylene plates and B-doped $\mathrm{Al}$ sheet were adhered to each other, and each $\mathrm{Au}$ foil sample for neutron monitoring was pasted onto the center of the plate.

\section{Activity measurement}

The activity of one Au foil sample was measured using a Ge detector (Canberra, GL2018, Canberra Industry Inc., Meriden, CT) coupled with a multichannel analyzer (MCA, Inspector 2000, Canberra Industry Inc., Meriden, CT). The detection efficiency for ${ }^{198} \mathrm{Au}$ gamma-rays in $\mathrm{Au}$ foil was obtained using efficiency calibration software (Canberra, ISOCS/LabSOCS, Canberra Industry Inc., Meriden, CT). Each $\mathrm{Au}$ foil sample was pasted onto a sheet and contacted with an imaging plate (Fujifilm, BAS-SR2040) for 1 hour. Laser scanning of the image plate was performed by an image analyzer (GE Healthcare Life Sciences, Typhoon FLA7000). The relative activity of the $\mathrm{Au}$ foil was obtained simultaneously by the photostimulated luminescence in the same area of the Au foil image $[7,8]$.

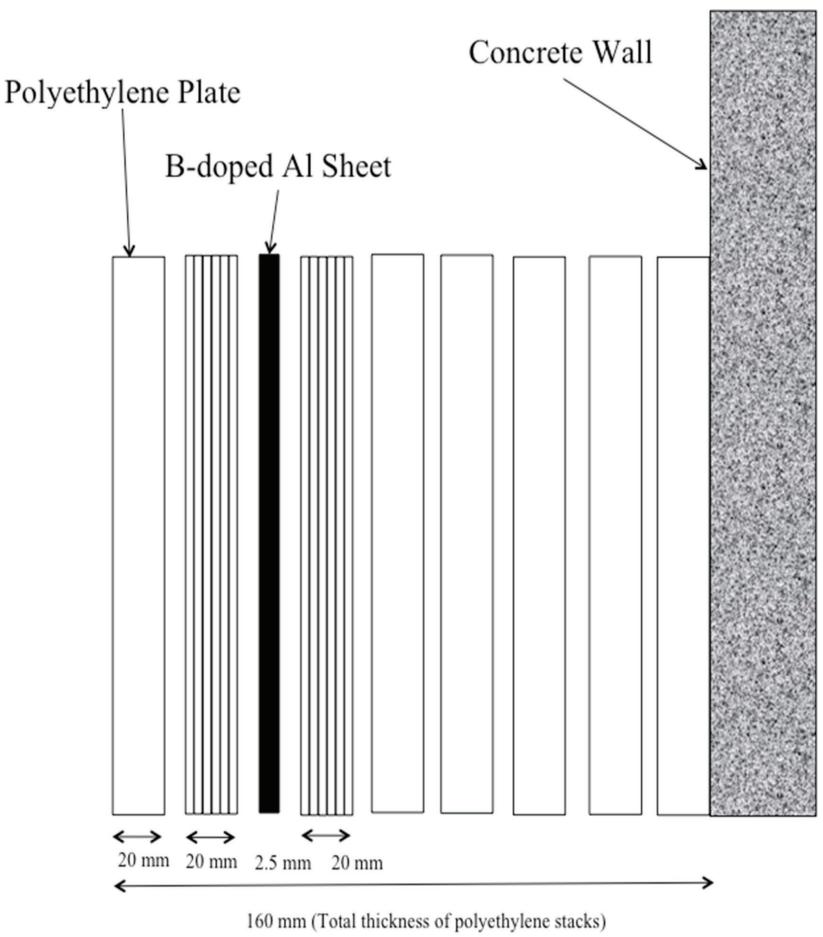

Fig. 2. Example of the irradiation setup with a combination of polyethylene plates and a B-doped Al sheet.

\section{Results and Discussion}

Figure 3 presents the depth profile of the relative activity of ${ }^{198} \mathrm{Au}$, which was normalized to the activity at the surface. In Case 1, the activity of ${ }^{198} \mathrm{Au}$ is maximized at a depth of $20 \mathrm{~mm}$, decreases as the depth increases from $20 \mathrm{~mm}$ to $120 \mathrm{~mm}$, and then increases again. Thus, the maximum thermal neutron fluence occurred at a depth of $20 \mathrm{~mm}$. In this case, the go-behind effect of surrounding neutrons is observable at depths greater than $120 \mathrm{~mm}$.

In Cases 2 and 3, the activity of ${ }^{198} \mathrm{Au}$ clearly decreases at the insertion position. Near each B-doped Al sheet, a Vshape is observable due to its neutron absorption effects. The neutron fluence increases as the depth increases beyond the insertion position of $40 \mathrm{~mm}$ in Case 2, and the maximum is observable at a depth of $60 \mathrm{~mm}$. In Case 3, the neutron absorption effect is greater than that in Case 2 , and a second increase is not clearly observable due to the go-behind effect of fast neutrons.

We also evaluated the activation of the concrete wall. In this work, the activation of the entire polyethylene plate stack in Case 1 and the activation of the parts of the stacks behind the B-doped $\mathrm{Al}$ sheets in Cases 2 and 3 correspond to the activation of the concrete wall. To determine the polyethylene thickness that would yield effective activation reduction, least-squares fitting of the relative activity of ${ }^{198} \mathrm{Au}$ in Cases 1-3 was performed using a biquadratic function: $A=\mathrm{a}_{0}+\mathrm{a}_{2} X^{2}$ $+\mathrm{a}_{3} X^{3}+\mathrm{a}_{4} X^{4}$. As shown in Figure 4 , we divided the curves into seven fitting regions. The obtained parameters are listed in Table 1. For the seventh region, corresponding to depths of more than $120 \mathrm{~mm}$, we assumed exponential decay according to the function $A=\exp \left(\mathrm{a}_{0}+\mathrm{a}_{1} X\right)$ to cancel the go-around

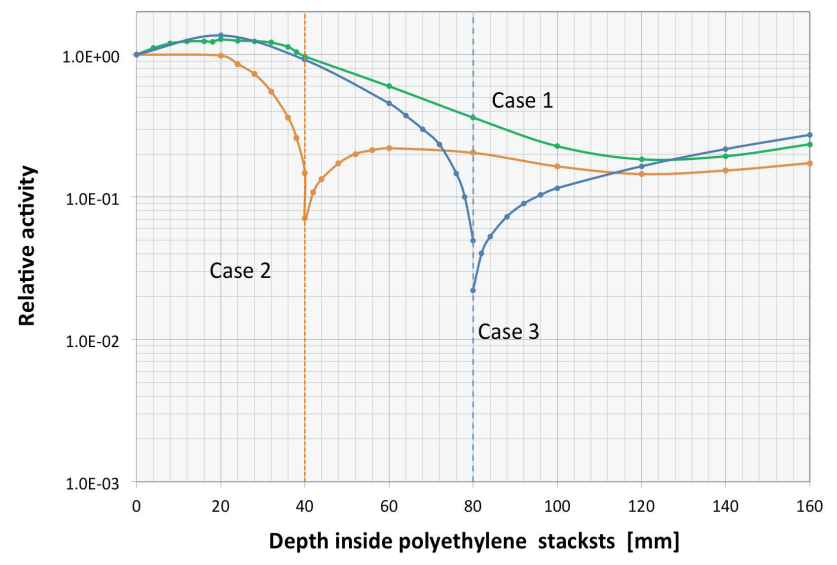

Fig. 3. Depth profile of ${ }^{198} \mathrm{Au}$ activity inside the polyethylene plates. 


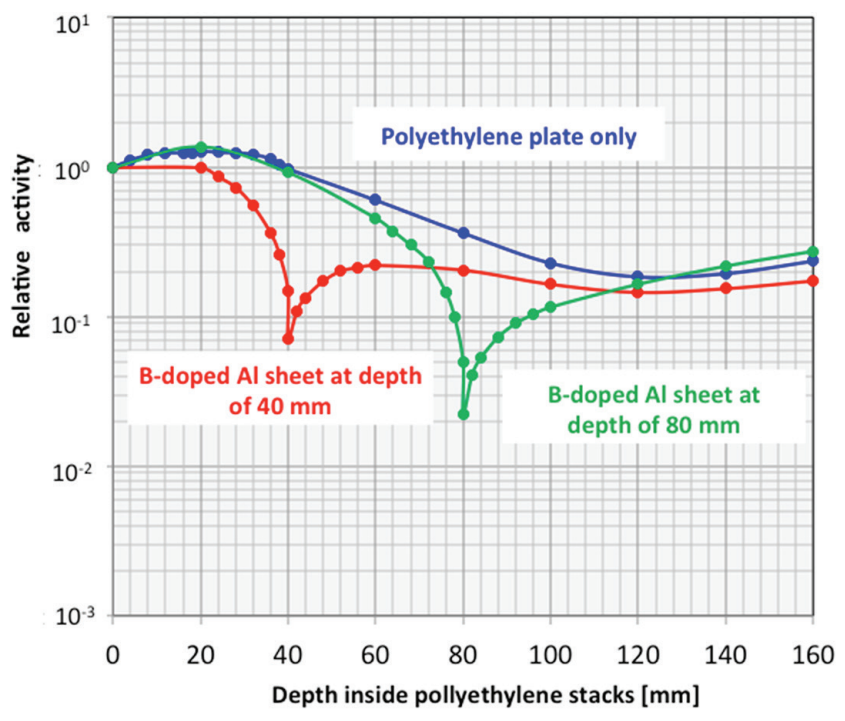

Fig. 4. Curve fitting conditions of the relative activity of ${ }^{198} \mathrm{Au}$.

Table 1. Parameters of the Six Regions Obtained by Least-Squares Fitting

\begin{tabular}{cccccc}
\hline & $\mathrm{a}_{0}$ & $\mathrm{a}_{1}$ & $\mathrm{a}_{2}$ & $\mathrm{a}_{3}$ & $\mathrm{a}_{4}$ \\
\hline (1) & $1.04 \mathrm{E}+00$ & $3.18 \mathrm{E}-02$ & $-7.58 \mathrm{E}-04$ & $-4.64 \mathrm{E}-07$ & $0.00 \mathrm{E}+00$ \\
(2) & $2.33 \mathrm{E}+00$ & $-4.12 \mathrm{E}-02$ & $2.19 \mathrm{E}-04$ & $1.16 \mathrm{E}-07$ & $-2.80 \mathrm{E}-09$ \\
(3) & $1.00 \mathrm{E}+00$ & $3.24 \mathrm{E}-02$ & $-2.16 \mathrm{E}-03$ & $2.94 \mathrm{E}-05$ & $-2.25 \mathrm{E}-07$ \\
(4) & $-2.02 \mathrm{E}+00$ & $1.05 \mathrm{E}-01$ & $-1.77 \mathrm{E}-03$ & $1.28 \mathrm{E}-05$ & $-3.40 \mathrm{E}-08$ \\
(5) & $1.00 \mathrm{E}+00$ & $6.06 \mathrm{E}-02$ & $-2.82 \mathrm{E}-03$ & $3.86 \mathrm{E}-05$ & $-1.84 \mathrm{E}-07$ \\
(6) & $-1.98 \mathrm{E}+01$ & $7.86 \mathrm{E}-01$ & $-1.17 \mathrm{E}-02$ & $7.78 \mathrm{E}-05$ & $-1.93 \mathrm{E}-07$ \\
\hline
\end{tabular}

effect of fast neutrons. In this case, the fitting values of $\mathrm{a}_{0}$ and $\mathrm{a}_{1}$ were 1.01 and -0.0243 , respectively. The integral of the activity to a depth of $1,000 \mathrm{~mm}$ was then estimated in each case. This value is proportional to the number of thermal neutrons absorbed by the shield.

Next, we estimated the neutron reduction rates using several types of shields to assess the effectiveness of each shield type. We also evaluated the reduction rate of the maximum activity behind the shield in each case. The results are presented in Table 2.

Using a 40 -mm-thick polyethylene plate as a shield reduced the neutron rate by $54 \%$. When a B-doped $\mathrm{Al}$ sheet was also inserted, the thermal neutron rate was reduced by $78 \%$.

The 80-mm-thick polyethylene plate shield provided neutron reduction by $82 \%$, while the thermal neutron rate was reduced by $89 \%$ by also inserting a B-doped $\mathrm{Al}$ sheet. The corresponding maximum specific activity reduction rates indicate that inserting an $\mathrm{Al}$ sheet containing $\mathrm{B}$ (30 wt\%) effectively reduces the residual activity behind the additional shield. However, the difference between the maximum activ-
Table 2. Neutron Reduction Rates and Maximum Activity Reduction Rates behind Additional Shields

\begin{tabular}{lcc}
\hline Shield type & $\begin{array}{c}\text { Neutron reduction } \\
\text { rate }(\%)\end{array}$ & $\begin{array}{c}\text { Maximum activity } \\
\text { reduction rate (\%) }\end{array}$ \\
\hline No shield & 0 & - \\
Polyethylene plate $(40 \mathrm{~mm})$ & 54 & 76 \\
Polyethylene plate $(40 \mathrm{~mm})+$ & 78 & 16 \\
$\quad$ B-doped Al sheet & & 28 \\
Polyethylene plate $(80 \mathrm{~mm})$ & 82 & 14 \\
$\begin{array}{l}\text { Polyethylene plate }(80 \mathrm{~mm})+ \\
\text { B-doped Al sheet }\end{array}$ & 89 & \\
\hline
\end{tabular}

ity reduction rates achieved using the 40- and 80-mm-thick polyethylene plates is not substantial.

\section{Conclusion}

The effect of neutron shielding by a B-doped Al sheet has been observed clearly by using the activation detector method. It was found that a 40-mm-thick polyethylene plate with a B-doped $\mathrm{Al}$ sheet was determined to be the most effective combination for neutron shielding and activity reduction. In this work, the proton energy was $30 \mathrm{MeV}$, which is greater than that used in typical PET cyclotrons. To confirm the shielding effect of a PET cyclotron facility, we will perform a similar experiment of $18 \mathrm{MeV}$ proton irradiation as the next step.

\section{References}

1. Fujibuchi T, Nohtomi A, Baba S, Sasaki M, Komiya I, Umedzu Y, Honda H. Distribution of residual long-lived radioactivity in the inner concrete walls of a compact medical cyclotron vault room. Ann. Nucl. Med. 2015;29:84-90.

2. Ogata Y, Ishigure N, Mochizuki S, Ito K, Hatano K, Abe J, Miyahara H, Masumoto K, Nakamura H. Distribution of thermal neutron flux around a PET cyclotron. Health Phys. 2011;100:S60S66.

3. Masumoto K, Miura T, Bessho K, Matsumura H, Toyoda A, Wang Q, Shibata T. Evaluation of radioactivity in concrete samples obtained from various accelerator facilities. Asian and Oceanic Congress for Radiation Protection (AOCRP)-II. Bejing, China. October 9-13, 2006.

4. Wang Q, Masumoto K, Bessho K, Matsumura H, Miura T, Shibata T. Evaluation of the radioactivity in concrete from accelerator facilities. J. Radioanal. Nucl. Chem. 2007;273:55-58.

5. Masumoto K, Toyoda A, Eda K, Izumi Y, Shibata T. Evaluation of radioactivity induced in the accelerator building and its application to decontamination work. J. Radioanal. Nucl. Chem. 2003; 
255:465-469.

6. Kinno M, Kimura K, Ishikawa T, Nakamura T. Studies on induced activities and target nuclei in low-activation concrete structure for thermal neutron irradiation. J. Nucl. Sci. Technol. 2000;30(1):821-826.

7. Masumoto K, Toyoda A, Eda K, Ishihara T. Measurement of the spatial distribution of neutrons in an accelerator room by the combination of activation detectors and an imaging plate. Radiat. Safety Manage. 2002;1:12-16.

8. Masumoto K, Iijima K, Toyoda A, Wang Q. Evaluation of imaging plate technique coupled with activation detector as the passive neutron monitor. J. Radioanal. Nucl. Chem. 2007;271:297303. 